\title{
乡镇事业单位档案管理的质量保障体系的构建
}

\author{
卓钰敏
}

临沂市兰陵县大仲村镇中心卫生院

DOI:10.32629/er.v3i1.2397

[摘 要] 事业单位的档案管理水平对事业单位的发展起到了不如忽视的作用。本文主要分析了档案管理的作用,以及对事业单位档案管理当中 存在的问题进行了深度剖析,还提出了一些在档案管理当中提高质量保障体系的对策。希望能够对事业单位的档案管理工作起到一定的帮助, 以期得到指正。

[关键词] 事业单位; 档案管理；质量保障；对策

随着我国经济水平的不断提高, 乡镇事业单位将要进行不断的深入改 革, 人员管理的作用在不断的体现出来。在事业单位里, 人才的信息都是从 档案中体现出来的, 可以展示出整个事业单位的人员情况, 也是在人员晋 升时人才选择的一个重要依据 ${ }^{[1]}$ 。但是综观我国目前很多事业单位在对档 案进行管理的时候出现了很多的问题, 不管是在管理手段上还是管理的质 量都有待提高。

\section{1 档案管理的作用}

档案管理这项工作在事业单位存在的时候就已经有了, 对事业单位的 发展有着直接的影响作用。但是, 目前很多乡镇事业单位还没有认识到档案 管理对乡镇事业单位管理工作的作用, 导致对档案管理工作并把重视。档案 管理在乡镇事业单位发展的过程中起着特别重要的作用, 对整个事业单位 的发展意义非凡。首先, 档案管理工作的水平与事业单位发展之间存在着直 接的联系, 提高档案管理工作的水平将能够推动整个事业单位的发展。其 次, 档案当中记录了很多的工作事项, 承载了乡镇事业单位的工作职责。提 高档案管理的水平将有效缩减事业单位的工作时间和提高工作效率。由此, 我们可以发现加强对乡镇事业单位档案的管理, 将对乡镇事业单位的发展 和运营起到一个决定性的作用 ${ }^{[2]}$ 。

\section{2 档案管理的现存问题}

2. 1 管理态度问题

现在乡镇事业单位的档案管理问题当中还存在一个管理工作人员的 态度问题。档案管理工作人员的工作态度, 将决定档案管理工作能否高效 进行。现在很多乡镇事业单位的档案管理人员, 对档案管理工作认识不够 全面认为档案的管理只是系统数据的保存而已, 这会导致他们在档案管理 工作当中对自己的工作职责认知不清晰的情况发生, 对自己的工作定位无 法正确把握。档案管理工作是一项需要认真执行的工作, 容不得半点差错 的发生 ${ }^{[3]}$ 。如果档案管理人员在工作的过程中没有积极性, 对工作也不认 真负责没有在固定的时间对档案进行整理和分类, 那么档案会出现杂乱无 章的现象, 影响后续档案工作的展开。这种情况下一定要对档案管理人员 及时打预防针, 否则将会影响到整个事业单位的运行。只有提高档案管理 人员的工作态度, 档案管理工作才能得到突破, 并且实现乡镇事业单位档 案管理的质量保障。

\section{2体系问题}

乡镇事业单位的档案管理体系还不是特别完善, 在管理上面还存在着 特别多的问题, 这些问题的存在严重阻碍了事业单位的管理水平提高。事 业单位对档案管理的体系形成将对档案管理工作整体起到一个积极的影 响。在目前的大部分乡镇事业单位工作当中, 很多档案管理工作并没有建 立一个完善的体系, 大大落后于工作的标准。这种问题的存在使得档案管 理工作无法与档案管理要求相对应, 严重阻碍了档案管理水平的提升。现
在很多事业单位的工作比较繁重, 但是目前的档案记录方式还是无法应对 这么多信息量的记载。这种落后的档案记录方式, 给档案管理工作水平的 提升带来了一定程度上的阻碍。现代事业单位的工作量特别大, 要求档案 在能够容纳大量信息的同时还要在管理上具备便捷和有效性, 但是纵观目 前乡镇事业单位的情况还远远不能满足这项要求。所以在这种情况下更要 完善档案管理工作的体系, 进一步提高乡镇事业单位的档案管理水平。

\section{3 保障体系的对策}

3. 1端正管理人员工作态度

档案管理人员的工作态度对提高档案管理工作有着不可忽视的作用。 档案管理人员在工作的过程中一定要对档案管理这项工作引起高度的重 视, 树立一个良好的工作态度, 并且找准自己的工作定位, 明白自己的职责 所在。一定要严格按照单位的规章制度进行办事, 规范好自己的工作流程。 面对上级安排的工作一定要认真及时地完成, 并且在发现问题如果自己无 法处理的情况下进行向上级汇报。在工作的过程中要不断去完善自己的档 案管理技能, 不断提高自己的工作效率和学会精简办事。只有档案管理人 员的工作态度端正, 他们才能认识到自身的职责并且规范自己在工作当中 的行为。很多档案管理问题都是因为档案管理人员不够认真负责导致的, 比如档案记录错误或者信息的遗失, 在端正了档案管理人员的工作态度之 后这种现象将会得到有效的减少, 进一步提高档案管理工作的水平并且推 动乡镇事业单位的发展。

\section{2 完善管理体系}

乡镇事业单位在提高档案管理质量的同时, 还要及时去完善档案管理 工作的体系。要利用多种方式去优化档案管理的渠道, 提高档案管理的经 费和档案管理系统的运营维护费用。建立一个档案管理基础设施费用的规 章制度, 做到特定的资金就用在特定的事情上面, 全面实现档案信息的管 理和整合。另外, 乡镇事业单位还要根据单位的具体情况设立专门的档案 管理部门, 实现专门管理档案工作的局面。这样, 才能在档案管理工作当中 发现问题并且及时处理, 保证档案管理工作能够顺利的运行。对档案管理 工作完善管理体系, 是特别重要的一项工作可以在一定程度上预防一些不 必要的的错误发生, 促使档案管理工作的水平提高。只有档案管理工作的 体系被完善, 档案管理人员在进行档案管理的时候才能做到有规矩可依, 实现自己的高效工作。很多乡镇事业单位在对档案进行管理的同时, 完善 了自己单位的管理体系之后取得了特别大的工作成效。

3. 3优化工作手段

在这个现代信息化技术已经被广泛运用的时代, 乡镇事业单位的档案 管理工作遇到了全新的挑战。以前纸质版的档案已经不适用于现代事业单 位的管理工作了, 比如容易受潮, 或者保存时间短。这些问题的出现使得纸 质档案已经无法适应当今的事业单位发展了。所以在这个时期, 事业单位 


\section{素质教育框架下的大学生诚信就业机制研究一以长春光华学院 为例}

郭全

长春光华学院

DOI:10.32629/er.v3i1.2333

[摘 要] 诚信是中华民族的传统美德,当前在我们一些大学生求职就业过程中存在着不讲诚信的现象,不仅损害了大学生自身形象,也损害用人 单位的利益,损害了学校的声誉, 也不利于整个社会诚信体系的构建。面对这一现象, 如何对大学生开展诚信就业教育就成为了我们研究的一项 重要内容。

[关键词] 素质教育; 诚信教育; 养成教育; 实施方案

长春光华学院把对大学生的诚信教育纳入到养成教育当中, 并把她作 为立德树人的有利抓手, 更是素质教育的重要组成部分, 长春光华学院高 度重视学生养成教育, 把养成教育作为学校人才培养的重要目标贯彻实 施。学校从建立相关的管理制度、出台具体的实施方案、采取相关的保障 措施来强化大学生诚信教育, 从而形成学校整体的诚信就业机制。

\section{1 建立相关的管理制度}

学校于2016年按照《教育部办公厅关于进一步加强和完善高校毕业生 就业状况统计报告工作的通知》 (教学厅 (2004) 7号) 、教育部办公厅关 于做好全国普通高校未就业毕业生统计服务工作的通知 (教学厅函 (2016) 13 号) 等文件精神, 结合学校实际制定了《长春光华学院毕业生就业状况统 计管理办法》, 明确了对此项工作的组织领导、统计分类、毕业生就业状 况核查及相关工作要求。

1.1毕业生就业统计按照校、院、班三级核查的方式进行。

1. 2 明确了教育部 “四不准” 的要求。即不准以任何方式强迫毕业生 签订就业协议, 不准将毕业证书、学位证书发放与签约挂钩, 不准劝说毕业 生签订虚假协议, 不准将顶岗实习、见习证明材料作为就业证明材料。

1. 3加强对毕业生的诚信教育。要求毕业生如实申报个人就业状况, 如实回答教育部第三方调查。若发现有毕业生有不诚信行为, 将对毕业生 及相关学院进行通报。

1. 4 明确了统计工作的时间结点。6月10日前各个学院完成本院毕业生 就业状况的第一次核查, 就业指导中心依据核查结果完善数据信息报省就 业指导中心, 完成就业派遣方案数据的上报工作。8月10日前各个学院完成 本院未就业毕业生就业状况的第二次核查, 就业指导中心负责审核各院调

一定要及时转变自己的工作方式, 将信息化技术使用到档案的管理工作上 来。为了可以更好的把信息化技术融入到档案的管理工作当中, 需要建立 一个专业的档案管理系统, 并且把信息化技术运用到这个系统当中, 实现 档案的高效管理。在这个过程当中, 不仅能够保证档案信息的完整性, 还有 利于减少档案管理当中操作的时间更加方便操作, 实现高效办公。优化档 案管理的方式, 不仅仅有效缩减了档案管理工作的时间还可以提高档案管 理人员的办事效率, 对整个事业单位的管理工作都是有帮助的。

\section{4 结束语}

综上所述, 在乡镇事业单位档案的管理工作当中一定要做到严于律己, 跟进时代的发展潮流, 促进乡镇事业单位档案管理工作的质量提高。另外, 一定要从事业单位的各个部门抓起, 做好每一个部门的档案管理工作, 这 样才能方便整个事业单位工作的运行。在对乡镇事业单位的档案管理当中,
查结果上报离校未就业毕业生情况, 生成我校八月末的初次就业数据报省 高等学校毕业生就业服务中心审批。12月15日前各个学院完成对毕业生就 业状况的第三次统计, 就业指导中心依据核查结果完善数据信息上报教育 部, 完成年底就业率的上报。三次核查结果须由院长和副书记签字, 报就业 指导中心备案。

\section{2 出台相关的实施方案}

为实现我校养成教育提出的两大目标, 一是使我们的学生得实惠。二 是使我们的学校出品牌。进一步把养成教育深化、细化、做实, 长春光华 学院就业指导中心从就业工作的角度出发, 进一步探索养成教育如何与就 业工作相接轨, 养成学生的哪些好习惯将对就业工作有促进作用, 对未来 大学生的就业择业、成功成才起到关键性作用。就业指导中心针对目前大 学生群体在就业过程中缺乏责任感、责任意识淡薄的表现, 从本职工作的 角度出发制定了《长春光华学院就业工作养成教育实施方案》, 加强大学 生责任意识的培养, 构建诚信就业工作制机, 对于推动社会良性发展, 构建 和谐社会具有重要意义。

2.1 目标设计。学校把养成教育的培养目标确立为培养 “五有两能” 的应用型人才, 即胸中有志、心中有情、眼中有活儿、身上有劲儿、腹中 有才、伸手能做、张嘴能说。我们结合与就业工作相关的系列好习惯的养 成和培育, 着力把毕业生培养成学习有目标、发展有动力、职业有方向、 上岗有干劲、工作有创新的应用型人才。

2. 2 项目设计。诚信就业养成教育实施方案主要包括对大学生职业生 涯规划意识养成、就业责任意识的养成、正确择业观的养成三个部分。

2.2.1养成职业生涯规划意识。从近几年我校应届毕业生的整体情况 要根据事业单位的实际情况去制定适合自己单位的档案管理方式, 建设一 个良好的单位运行框架保障档案管理工作的质量。只有提高了档案管理工 作的水平, 才能实现乡镇事业单位档案管理的质量保障, 并且乡镇事业单 位才能平稳的发展。

\section{[参考文献]}

[1]罗濒鸣.事业单位档案管理的质量保障体系建设探析 “美丽中国” 的理解[J].现代国企研究,2018(16):105.

[2]吕峰.事业单位档案管理的质量保障体系建设探析 [J].兰台世 界,2018(04):61-62.

[3]程江余.浅谈事业单位档案管理工作的优化方法建设探析[J].才 智,2018(10):208. 